\title{
BILATERAL IRREVERSIBLE BLINDNESS
}

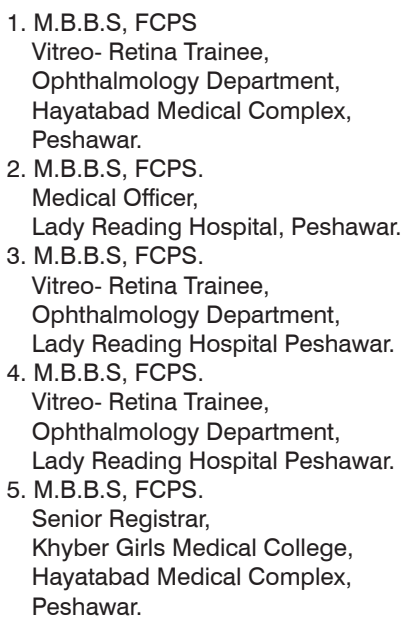

Correspondence Address:

Dr. Asif Iqbal

House No; 279

Street 10, Sector E-2, Phase- 1 Hayatabad, Peshawar. dcasif@yahoo.Com.

Article received on:

02/07/2014

Accepted for publication:

27/09/2014

Received after proof reading:

$15 / 12 / 2014$

\author{
Dr. Asif Iqbal', Dr. Muhammad Idrees², Dr. Bilal Bashir ${ }^{3}$, Dr. Mubashir Rehman ${ }^{4}$, \\ Dr. Omer Khan Orakzai ${ }^{5}$.
}

ABSTRACT...Objective: To find out the causes of bilateral irreversible blindness in patients of different age groups in District Swabi. Design: It is a prospective observational study of one hundred and eighty nine consecutive blind cases. Place and Duration of Study: The study was conducted from July 2010 to June, 2012 at the Ophthalmology Department of District Headquarter Hospital, Swabi. Subjects and Methods: Informed consent was taken from the patient or guardian of the patient. Patients fulfilling inclusion and exclusion criteria were included in the study. A standard proforma was designed and entries were made regarding present, past and family history, thorough ocular examination of every patient was performed on slitlamp with relevant biomicroscopic aids and posterior segment examination was conducted with direct as well as indirect ophthalmoscope. Biomicroscopy was performed as and when required. Intraocular pressure using schiotz tonometer, corneal diameters, retinoscopy and ocular mobility were noted and relevant investigations were performed when needed. Children and mentally retarded patients were examined using short general anaesthesia. Results: Of 189 patients $61.4 \%$ were males and $38.6 \%$ were females. Congenital Causes were present in $49.7 \%$ and acquired causes in $50.3 \%$. Diseases accounted for $88.9 \%$, trauma in $10.1 \%$ and unknown causes in $1.1 \%$ cases. Congenital diseases included congenital glaucoma in $35.1 \%$, retinitis pigmentosa in $29.7 \%$ and albinism in $19.1 \%$ cases. Acquired diseases included primary glaucoma in $33.8 \%$, diabetic retinopathy $23 \%$, secondary glaucoma in $17.5 \%$ and childhood infection in $10.8 \%$ cases. Corneal findings included corneal opacity in $31.2 \%$, corneal edema in $4.8 \%$ and absent cornea in $7.4 \%$. Optic nerve findings included optic atrophy in $16.4 \%$, glaucomatous optic atrophy in $16.9 \%$, new vessels in $9.5 \%$. Retina findings included retinal dystrophy in $14.3 \%$, maculopathy in $5.3 \%$, chorioretinopathy in $0.5 \%$, vascular retinopathy and hypopigmentation in $9.5 \%$ each respectively. Conclusions: Irreversible blindness is more common in children and young adults and mostly males are affected. Glaucoma is the commonest cause followed by retinitis pigmentosa and albinism in this study.

Key words: Irreversible blindness, Glaucoma.

Article Citation: Iqbal A, idrees M, Bashir B. Rehman M, Orakzai OK. Bilateral irreversible blindness in District Swabi. Professional Med J 2014; 21(6):1258-1263.

\section{INTRODUCTION}

Blindness, a major health problem has received little attention in under developed countries where the vast majority of world's blind live. According to WHO estimates, 45 million people are blind globally ${ }^{1}, 2$ million in Latin America, 6 million in Africa and 20 million in Asia $^{2}$. In Pakistan, about 2 million people are blind and blindness rate is $1.08 \% 2$. The prevalence of blindness in Khyber Pakhtoonkhwa is $1 \%^{3}$. District Swabi has a population around 1.8 million. The disabled persons constitute $3.6 \%$ of the total population. The disability is classified as blind, deaf, mute, crippled, insane and mentally retarded ${ }^{4}$.

\section{METHODS}

We studied 189 consecutive blind cases attending Ophthalmology Department at District Headquarter Hospital, Swabi from July 2010 to June 2012. Blindness was defined as best corrected visual acuity of $<3 / 60(<20 / 400)$ in the better eye according to the 'Strategies for the Prevention of Blindness, National Plan, WHO, 1997. Patients with best corrected visual acuity better than $3 / 60$ in better eye, uniocular blind patients, unwilling and uncooperative patients were excluded from the study. Informed consent was taken from the patient or guardian of the patient. A standard proforma was designed and entries were made regarding detailed history, 
which included relevant personal data, onset of disease, duration and severity, past history of usage and change of glasses, trauma, inflammatory conditions, consultations with ophthalmologists and medications were recorded. Family history of diseases was inquired. Patients were specifically asked about any systemic disease like diabetes mellitus and hypertension.

Best corrected and uncorrected visual acuity was measured both for distance and near. Different tests were performed depending upon age of the patient by a trained ophthalmic technician as follows;

1. Less than three months old by head turn to light reflex.

2. 3-24 months old with preferential looking.

3. 2- 3 years old with matching tests.

4. 3- 4 years old with Kay pictures.

5. 4- 5 years old and adults with Snellen "E" chart.

Examination of adnexa was recorded. Anterior segment was examined on slit-lamp with relevant biomicroscopic aids, while posterior segment examination was conducted with direct and indirect ophthalmoscopes. Biomicroscopy was performed as and when required. Intraocular pressure using schiotz tonometer, corneal diameters, retinoscopy and ocular motility were also noted. Relevant investigations were performed where needed. Children and mentally retarded patients were examined under short general anaesthesia.

Data was then entered and analyzed using SPSS version 20 , frequencies and percentages were calculated.

\section{RESULTS}

This was a hospital based prospective observational study. Total of one hundred and eighty nine patients attending the Out Patient Department were noted in two years.

Out of one hundred and eighty nine patients, $33.9 \%(n=64)$ patients were in the age range of $1-15$ years. Males were $61.4 \%(n=116)$ and females were $38.6 \%(n=73)$. Age and sex distribution is shown in (Table I).

\begin{tabular}{|c|c|c|c|}
\hline \multirow{2}{*}{$\begin{array}{c}\text { Age in } \\
\text { years }\end{array}$} & \multicolumn{2}{|c|}{ Sex of patient } & \multirow{2}{*}{ Total } \\
\hline $1-15$ & Male & Female & \\
\hline $16-30$ & 36 & 28 & $64(33.9 \%)$ \\
\hline $31-45$ & 25 & 12 & $47(24.9 \%)$ \\
\hline $45-60$ & 20 & 16 & $41(21.7 \%)$ \\
\hline Total & 116 & 73 & $37(19.6 \%)$ \\
\hline \multicolumn{3}{|c|}{ Table-I. Age and Gender Distribution. } \\
\hline
\end{tabular}

Regarding nature of blinding diseas, results showed that $49.7 \%(n=94)$ patients were having congenital diseases whereas, $50.3 \%(n=95)$ were having acquired diseases. Nature of blinding diseases and gender distribution is shown in (Table II).

\begin{tabular}{|c|c|c|c|}
\hline \multirow{2}{*}{ Nature } & \multicolumn{2}{|c|}{ Sex of patient } & Total \\
\cline { 2 - 3 } & Male & Female & \\
\hline Congenital & $60(31.7 \%)$ & $34(18.0 \%)$ & $94(49.7 \%)$ \\
\hline Acquired & $56(29.6 \%)$ & $39(20.6 \%)$ & $95(50.3 \%)$ \\
\hline Total & $116(61.4 \%)$ & $73(38.6 \%)$ & $189(100.0 \%)$ \\
\hline Table- II. Nature of disease and Gender Distribution.
\end{tabular}

Overall, common cause of blindness was due to different diseases affecting eyes and/ or multiple organs comprising $88.9 \%(n=168)$ patients followed by trauma in $10.1 \%(n=19)$ patients and unknown cause in $1.1 \%(n=2)$ patients. Cause of blindness and gender distribution is shown in (Figure-1).

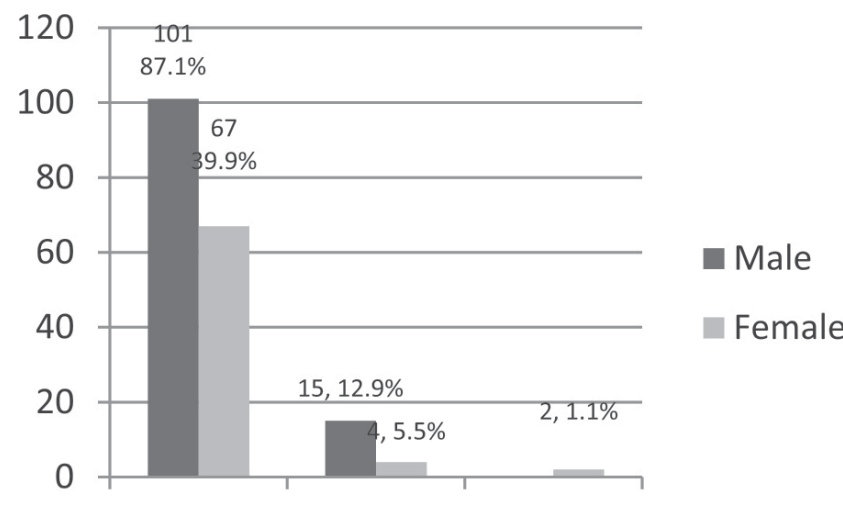

Diseases Trauma Unknown

Figure-1. Causes of irreversible blindness and Gender Distribution. 
Regarding congenital diseases causing irreversible blindness, congenital glaucoma was more common in $35.1 \%(n=33)$, retinitis pigmentosa in $29.7 \%(n=28)$, albinism in $19.1 \%$ $(n=18)$, Stargardt disease in $8.5 \%(n=08)$, uveal coloboma in $3.2 \%(n=03)$. Congenital diseases and sex distribution is shown in (Table III).

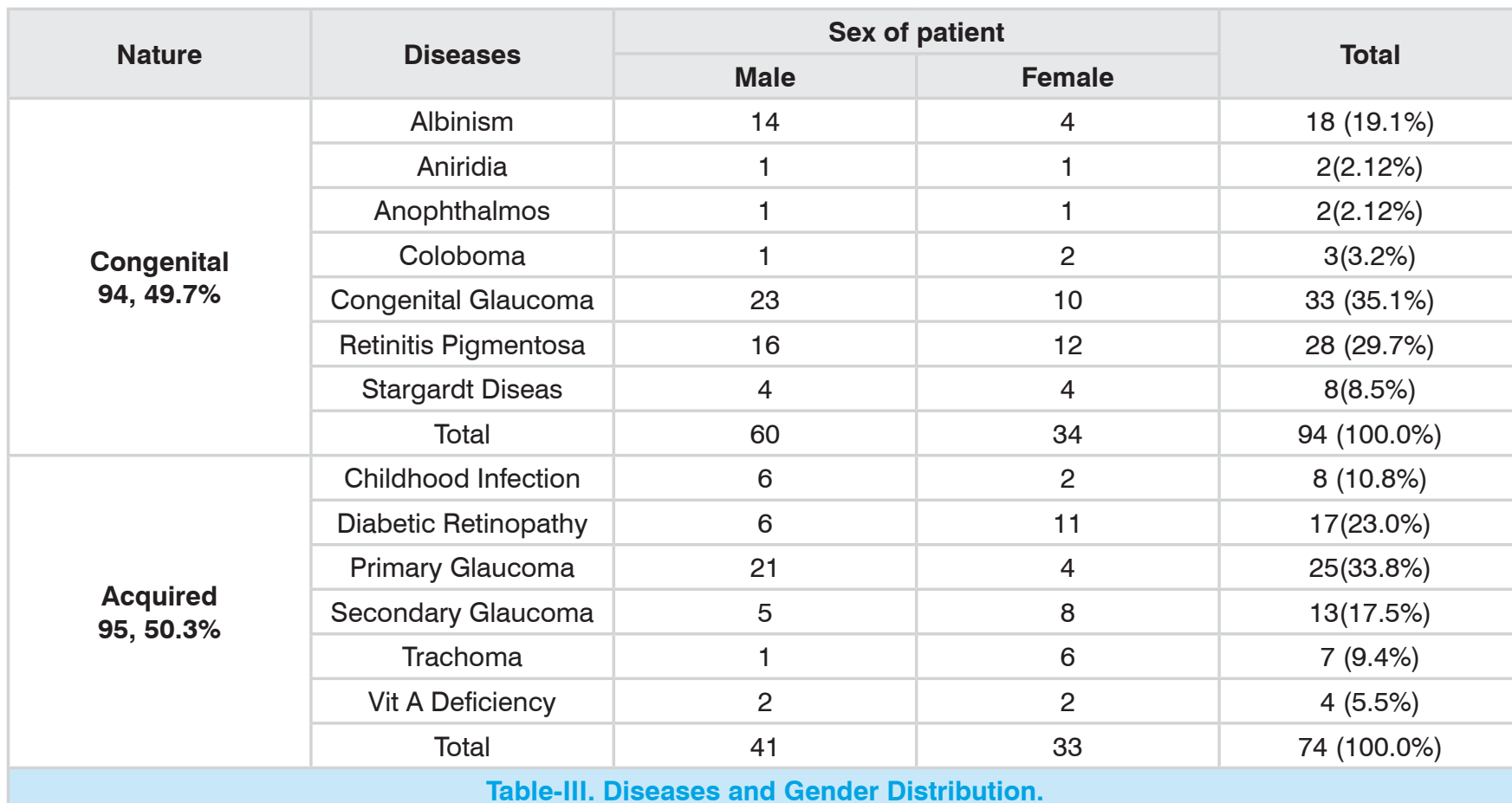

Acquired diseases causing irreversible blindness, primary open angle glaucoma was more common in $33.8 \%(n=25)$, diabetic retinopathy in $23.0 \%$ $(n=17)$, secondary glaucoma (steroid induced glaucoma and neovascular glaucoma) in $17.5 \%$ $(n=13)$, childhood infection in $10.8 \%(n=08)$ and trachoma in $9.4 \%(n=07)$. Acquired diseases and sex distribution is shown in (Table III).

Traumatic globe injury causing irreversible blindness was present in $10.1 \%(n=19)$ patients. Road traffic accident in $47.4 \%(n=09)$ patients, firearm in $21.1 \%(n=04)$, bomb blast and chemical splash in $10.5 \%(n=02)$ each. Traumatic injury and sex distribution is shown in (Table IV).

Regarding corneal causes of blindness, corneal opacity was present in $70.7 \% \quad(n=58)$ patients, corneal edema in $12.2 \% \quad(n=10)$ patients and absent globe in $17.1 \%(n=14)$ patients. Status of cornea and sex distribution is shown in (Table V).

Blindness due to optic nerve involvement comprised glaucomatous optic atrophy in $33.7 \%$

\begin{tabular}{|c|c|c|c|}
\hline \multirow{2}{*}{ Cause } & \multicolumn{2}{|c|}{ Sex of patient } & \multirow{2}{*}{ Total } \\
\cline { 2 - 3 } & Male & Female & \\
\hline Bomb Blast & 02 & 00 & $02(10.5 \%)$ \\
\hline Road Traffic Accident & 07 & 02 & $09(47.4 \%)$ \\
\hline Firearm Injury & 04 & 00 & $04(21.1 \%)$ \\
\hline Neurosurgery & 00 & 01 & $01(5.3 \%)$ \\
\hline Chemical Splash & 02 & 00 & $02(10.5 \%)$ \\
\hline Burns & 00 & 01 & $01(5.3 \%)$ \\
\hline Total & 15 & 04 & $19(100.0 \%)$ \\
\hline
\end{tabular}

Table-IV. Traumatic causes and Gender Distribution.

$(n=32)$, optic atrophy in $32.6 \%(n=31)$ and new vessels on disc (NVD) in $18.9 \%(n=18)$ patients. Condition of optic disc and sex distribution is shown in (Table V).

Blindness due to posterior segment involvement comprised retinal dystrophy in $32.2 \% \quad(n=29)$, maculopathy in $11.1 \%(n=10)$, Vascular retinopathy and hypopigmentation in $20 \%$ $(n=18)$ patients respectively. Posterior segment involvement and sex distribution is shown in (Table V). 


\begin{tabular}{|c|c|c|c|c|}
\hline \multirow{2}{*}{ Anatomical Location } & Signs & Male & Female & \multirow{2}{*}{ Total } \\
\hline \multirow{3}{*}{ Cornea } & Opacity & 36 & 22 & 58 \\
\hline \multirow{3}{*}{ Optic Nerve } & Edema & 05 & 05 & 10 \\
\hline & Atrophic & 17 & 14 & 31 \\
\hline \multirow{3}{*}{ Retina } & Cupped Atrophic & 24 & 08 & 32 \\
\hline & New Vessels & 06 & 12 & 18 \\
\hline & Dystrophy & 16 & 13 & 10 \\
\hline & Maculopathy & 05 & 05 & 01 \\
\hline & Chorioretinopathy & 01 & 00 & 18 \\
\hline & Vascular retinopathy & 06 & 12 & 18 \\
\hline & Hypopigmentation & 14 & 04 & 14 \\
\hline
\end{tabular}

\section{DISCUSSION}

In Pakistan, around 2 million people are completely blind and blindness rate is $1.08 \%{ }^{2}$. In this study, acquired causes $(50.3 \%)$ are more common than congenital causes (49.7\%). This is in agreement with Wajid SA et al ${ }^{5}$ who reported acquired causes in $91 \%$ and congenital causes in $6 \%$.

In this study glaucoma is the most common diseas, present in $37.5 \%(n=71)$ cases. This is in agreement with Wajid SA et $\mathrm{al}^{5}$ who reported glaucoma in $40 \%$ cases. The studies of Rosenburg ${ }^{6}$, Balatsoukas ${ }^{7}$ and Quigley ${ }^{8}$ documented glaucoma to be the second most common cause. Studies conducted by Dineen B et $\mathrm{al}^{9}$ and Memon MS et $\mathrm{al}^{10}$ reported glaucoma in $7.1 \%$ and $3.9 \%$ cases respectively declaring glaucoma as 4th common cause of irreversible blindness. The difference may be due to the fact that the sample size in these studies was very large as compared to our study.

Among glaucoma patients, primary glaucoma (open angle and close angle) is present in $35.2 \%$ $(n=25)$ cases. This is contrary to Pechucho AM et $\mathrm{al}^{11}$ who reported primary glaucoma in $50.2 \%$ cases and Wajid SA et $\mathrm{al}^{5}$ who reported it in $70 \%$ cases. Poverty, unawareness and delay in seeking treatment are the major factors responsible.

Congenital glaucoma comprises $46.4 \%(n=33)$. This is contrary to Wajid SA et al ${ }^{5}$ and Pechucho
AM et $\mathrm{al}^{11}$ who reported it in $25 \%$ and $7.6 \%$ cases respectively. Poverty, cousin marriages, multiparity, false beliefs and traditional medicines use all account for the high number of congenital glaucoma in our study.

Secondary glaucoma is present in $18.3 \%(n=13)$ cases including steroid induced and neovascular glaucoma. Wajid SA et al ${ }^{5}$ reported secondary glaucoma in $5 \%$ cases, all had neovascular glaucoma whereas, Pechucho AM et al ${ }^{11}$ reported $33.4 \%$ cases of secondary glaucoma including lens induced, steroid induced and neovascular glaucoma. Poor management of chronic uveitis, diabetes, hypertension and other diseases leading to neovascular glaucoma ${ }^{12}$ and use of unsupervised topical steroids for ocular surface allergies are possible causes of high prevalence of secondary glaucoma in our study.

Corneal blindness is present in $30.7 \% \quad(n=58)$ cases. Corneal opacity is present due to congenital glaucoma in $56.8 \%(n=33)$, childhood infection in $13.8 \%(n=8)$, trachoma in $12 \%(n=7)$, trauma in $10.3 \%(n=6)$ and Vitamin- A deficiency in $6.8 \%$ $(n=4)$. Dineen B et $\mathrm{al}^{9}$, Memon MS et $\mathrm{al}^{10}$ and See JLS et al ${ }^{13}$ reported corneal opacity in $11.8 \%$, $12.6 \%$ and $2.6 \%$ respectively. Memon MS et al ${ }^{10}$ reported corneal opacity in Khyber Pakhtoon Khwa as $16.5 \%$. Poor socio economic status, lack of education, malnutrition, overcrowding, poor hygiene, communicable eye diseases, traditional 
medicines use, lack of preventive public health, poor maternal performance during pregnancy and lactation, inadequate birth control, poor immunization and inadequate eye care services all contribute to high percentage of corneal blindness in our study.

Diabetic retinopathy accounts for $9 \% \quad(n=17)$ cases. This is in agreement to Dineen $\mathrm{B}$ et $\mathrm{al}^{9}$ who reported $0.2 \%$ of diabetic retinopathy in his study. Wajid SA et al 5 reported high prevalence of $33 \%$ cases. His finding was also supported by studies of Khan MD et $\mathrm{al}^{14}$ and Herse \& Gothwal ${ }^{15}$. Some of the reasons to explain this difference in the prevalence rates may be lack of awareness, inadequate health facilities and financial constraints.

Fundus dystrophy is reported in $30.1 \% \quad(n=57)$ cases. The most common is retinitis pigmentosa in $49.1 \%(n=28)$ cases followed by albinism in $31.5 \%(n=18)$, stargardt diseas in $14 \%(n=8)$ and uveal coloboma in $5.2 \%(n=3)$ cases. Wajid SA et $\mathrm{al}^{5}$ reported retinitis pigmentosa in $3 \%$ cases whereas $14.4 \%$ prevalence rate was reported in a survey conducted in district Swabi ${ }^{4}$.Factors responsible are illiteracy, cousin marriages, social constraints, poverty and multiparity.

Trauma is reported in $9 \%(n=17)$ cases. Road traffic accident being the most common in 47.4 $\%(n=9)$ followed by firearm injury in $2.1 \%$ ( $n=4)$. Males are predominantly affected with male to female ratio of 3.7: 1 . This is in agreement with Wajid SA et $\mathrm{al}^{5}$ who reported trauma in $70 \%$ cases with male predominance. This finding is also documented by Khan MD et $\mathrm{al}^{16}$ and other workers with male predominance. The important factors in trauma related blindness includes lack of education, awareness, preventive strategies and health care facilities.

Blindness due to unknown or unidentified causes is reported in $1.1 \%(n=2)$. This is in agreement with Wajid SA et al ${ }^{5}$ who reported it in $6 \%$ cases. It has also been reported that in about $13 \%$ cases etiology is unknown and in other $13 \%$ cases if good services are available, it could have been avoided $^{17}$.

\section{CONCLUSIONS}

From this study following conclusions are made:

1. Irreversible blindness affects all age groups but is more common in young age with male predominance.

2. Among the known etiologies, glaucoma turns out to be the commonest followed by corneal blindness and fundus dystrophies.

3. Basic reason behind majority of cases is poverty, illiteracy, lack of health care, false beliefs, traditional practices and treatment delay.

Copyright(c) 27 Sep, 2014.

\section{REFRENCES}

1. Jadoon $M Z$, Dineen $B$, Bourne RR, Shah SP, Khan MA, Johnson GJ, et al. Prevalence of blindness and visual impairment in Pakistan: The Pakistan National Blindness and Visual Impairment Survey. Invest Ophthalmol Vis Sci 2006; 4: 4749- 55.

2. National committee for prevention of blindness. Pakistan National Programme for the prevention of blindness: first five-year plan 1994-98 Islamabad. Ministry of Health, Special education and social welfare.

3. CHIP- SSI, Report PSA on Irreversible Blindness Swabi. 2005.

4. Wajid SA, Khan MD. Causes of Irreversible Blindness. JCPSP 11 (9): $561-64$.

5. Rosenberg LF. Glaucoma: early detection and therapy for prevention of vision loss. Am Fam Physian 1995; 52: 2289-98, 2303-4.

6. Balatsoukas DO, Sioulis C, Parisi A, Millar GT. Visual handicap in south-east Scotland. J R Coll Surg Edinb 1995; 40: 49-51.

7. Quigley HA. Number of people with glaucoma worldwide. Br J Ophthalmol 1996; 80: 389-93.

8. Dineen B, Bourne R R A, Jadoon Z, Shah S P, Khan M A, Foster A, Gilbert C E, Khan M D. Causes of blindness and visual impairment in Pakistan. The Pakistan national blindness and visual impairment survey. $\mathrm{Br}$ J Ophthalmol 2007; 91:1005- 10.

9. Memon MS. Prevalence and causes of blindness in Pakistan. J Pak Med Assoc 1992; 42(8): 196- 8.

10. Pechuho MA, Siddiqui SJ, Nangrejo KM, Sahto $A A$, Shah SIA, Qadir A. Audit of the glaucoma clinic. MC 
2011; 17(3): 25-8.

11. Krishnadas R, Ramakirshman R. Secondary glaucomas: The tasks ahead. Community Eye Health 2001; 14: 40- 2.

12. See JLS, Wong TY, Yeo KT. Trends in the Pattern of Blindness and Major Ocular Diseases in Singapore and Asia. Ann Acad Med Singapore 1998; 27: 540- 6.

13. Mohammad Z, Khan MD. Incidence of ocular complications of diabetes mellitus in Pakistan. Pak J Ophlhalmol 1992; 8: 7-11.
14. Herse P, Gothwal VK. Survey of visual impairment in an Indian tertiary eye hospital. Ind $\mathrm{J}$ Ophthalmol 1997; 45: 189- 93.

15. Khan MD, Mohammad S, Islam Z. Khattak MN. An 111/2 year review of ocular trauma in the North-West Frontier Province of Pakistan. Pak J Ophthalmol 1991; 7:15- 18.

16. Fafowora OF. Prevalence of blindness in a rural ophthalmically underserved Nigerian community. West Afr J Med 1996; 15: 228-31.

\section{Be there for others, but never leave yourself behind.}

